\title{
Electrodermal responses during appetitive conditioning are sensitive to contingency instruction ambiguity
}

Citation for published version (APA):

van den Akker, K., Nederkoorn, C., \& Jansen, A. (2017). Electrodermal responses during appetitive conditioning are sensitive to contingency instruction ambiguity. International Journal of Psychophysiology, 118, 40-47. https://doi.org/10.1016/j.ijpsycho.2017.06.004

Document status and date:

Published: 01/08/2017

DOI:

10.1016/j.ijpsycho.2017.06.004

Document Version:

Publisher's PDF, also known as Version of record

\section{Document license:}

Taverne

\section{Please check the document version of this publication:}

- A submitted manuscript is the version of the article upon submission and before peer-review. There can be important differences between the submitted version and the official published version of record.

People interested in the research are advised to contact the author for the final version of the publication, or visit the DOI to the publisher's website.

- The final author version and the galley proof are versions of the publication after peer review.

- The final published version features the final layout of the paper including the volume, issue and page numbers.

Link to publication

\footnotetext{
General rights rights.

- You may freely distribute the URL identifying the publication in the public portal. please follow below link for the End User Agreement:

www.umlib.nl/taverne-license

Take down policy

If you believe that this document breaches copyright please contact us at:

repository@maastrichtuniversity.nl

providing details and we will investigate your claim.
}

Copyright and moral rights for the publications made accessible in the public portal are retained by the authors and/or other copyright owners and it is a condition of accessing publications that users recognise and abide by the legal requirements associated with these

- Users may download and print one copy of any publication from the public portal for the purpose of private study or research.

- You may not further distribute the material or use it for any profit-making activity or commercial gain

If the publication is distributed under the terms of Article $25 \mathrm{fa}$ of the Dutch Copyright Act, indicated by the "Taverne" license above, 
Registered Reports

\title{
Electrodermal responses during appetitive conditioning are sensitive to contingency instruction ambiguity
}

\author{
Karolien van den Akker*, Chantal Nederkoorn, Anita Jansen \\ Faculty of Psychology and Neuroscience, Department of Clinical Psychological Science, Maastricht University, P.O. Box 616, 6200 MD Maastricht, The Netherlands
}

\section{A R T I C L E I N F O}

\section{Keywords:}

Appetitive conditioning

Food conditioning

Electrodermal responses

Contingency instructions

Ambiguity

\begin{abstract}
A B S T R A C T
Studies on human appetitive conditioning using food rewards can benefit from including psychophysiological outcome measures. The present study tested whether the skin conductance response can function as a measure of differential responding in an appetitive conditioning paradigm including an acquisition and extinction phase, and examined which time window during a trial is most sensitive to conditioning effects. As a secondary aim, the effects of ambiguous vs. non-ambiguous contingency instructions on conditioned responses (skin conductance responses, US expectancies, chocolate desires, and CS evaluations) were assessed. Results indicated differential skin conductance responses in an anticipatory time window and during unexpected omission of the US in early extinction. Interestingly however, anticipatory responses were only found for participants who received ambiguous contingency instructions - possibly indicating a call for additional processing resources in response to the ambiguous CS + . Further, ambiguous instructions slowed the extinction of US expectancies but did not influence chocolate desires and CS evaluations. It is concluded that skin conductance can function as a sensitive measure of differential responding in appetitive conditioning, though its sensitivity might depend on the specific task context.
\end{abstract}

\section{Introduction}

The prevalence of overweight and obesity has reached epidemic proportions. Currently, more than two-thirds of all U.S. adults are either overweight or obese (Ogden et al., 2014). Experts agree that the changed food environment is largely responsible for this (Swinburn et al., 1999), since its abundant food cues can easily elicit appetitive responses such as food cravings that promote overeating. Pavlovian learning has been proposed to play an important role in the development of these appetitive responses: after repeated pairings of a stimulus (e.g., the sight and smell of food, or a certain context) with food intake, the stimulus becomes a predictor (food cue) for intake that promotes appetitive responses and food intake (Bouton, 2011; Jansen, 1998; Jansen et al., 2011).

In line with a learning-based account, conditioning studies have shown that after a few pairings of a neutral stimulus (e.g., a box) with food intake (e.g., eating a piece of chocolate; unconditioned stimulus or US), this stimulus (conditioned stimulus + or $\mathrm{CS}+$ ) elicits conditioned appetitive responses (CRs), relative to a stimulus not followed by intake $(\mathrm{CS}-$ ). These responses generally diminish when the CS + is no longer followed by the US during extinction (e.g., Jansen et al., 2016; van den Akker et al., 2014; van den Akker et al., 2015; Van Gucht,
Vansteenwegen, Beckers, \& Van den Bergh, 2008). CRs that have been examined in these human appetitive conditioning studies often include psychological (self-reported US expectancies, cravings or desires to eat, and CS evaluations) and sometimes behavioural responses (food consumption or choice, and computer tasks) (Bongers et al., 2015; van den Akker et al., 2013; Van Gucht, Vansteenwegen, Van den Bergh, \& Beckers, 2008). There are limitations, however, to relying solely on self-report and behavioural measures. For example, their assessment may alter responses on subsequent measurements (Gawronski et al., 2015; Lipp and Purkis, 2006), and self-report measures in particular can be sensitive to experimental demand (e.g., Lipp, 2006). In addition, verbal/cognitive and behavioural measures likely do not cover all indices of (appetitive) learning, since multiple response systems are thought to be involved in conditioning (Beckers et al., 2013; Delamater and Oakeshott, 2007).

Psychophysiological measurement of conditioned appetitive responding may overcome at least some of these limitations. Although several psychophysiological measures may be suitable for measuring differential responding in appetitive conditioning (Blechert et al., 2016; Franken et al., 2011; Meyer et al., 2015; O'Doherty et al., 2003), one particularly promising, easy-to-use, and nonintrusive measure is skin conductance. Skin conductance measures activity of the sympathetic

\footnotetext{
* Corresponding author.

E-mail address: karolien.vandenakker@maastrichtuniversity.nl (K. van den Akker).
} 
nervous system which is thought to reflect arousal (Dawson et al., 2007). Such arousal can originate from various cognitive and emotional processes (Critchley, 2002). Skin conductance is heightened during exposure to the sight and smell of palatable food and other appetitive substances (e.g., Carter and Tiffany, 2001; Nederkoorn et al., 2000), and it is widely used as a measure of differential responding in fear conditioning studies, in which it may primarily index explicit learning about the CS-US contingencies (Hamm and Weike, 2005). In the appetitive field, several conditioning studies have examined skin conductance, reporting a successful acquisition of conditioned skin conductance responses to reward-associated CSs (e.g., Andreatta and Pauli, 2015; Glautier et al., 1994; Klucken et al., 2015; Kruse et al., 2017; but see Field and Duka, 2001). The USs that were used in these studies rarely involved food intake, however. One study that used a food US reported differential skin conductance responses during exposure to a food-associated CS + (a shape; Andreatta and Pauli, 2015). However, this $\mathrm{CS}+$ (but not the $\mathrm{CS}-$ ) was always accompanied by a picture of the food US. Since food pictures are potent CSs on their own that elicit appetitive responses (Boswell and Kober, 2016), it is impossible to determine whether differential responding was due to presentation of the existing cue (food picture) or due to the newly conditioned cue i.e., it is unclear whether differential skin conductance responses reflected conditioning effects.

Skin conductance can be measured in different time windows during a conditioning trial (Boucsein, 2012; Prokasy and Kumpfer, 1973). In fear conditioning studies, it is often measured directly after presentation of a CS (first-interval response or FIR), or, in case of longer CS-US intervals, in the period prior to US delivery (second-interval response or SIR; Lovibond et al., 2008; Prokasy and Ebel, 1967). In addition to measuring skin conductance during an anticipation period, one may also observe differential responding after unexpected omission of a shock US (i.e., on a non-reinforced CS + trial after CS offset; Dunsmoor and LaBar, 2012; Grings et al., 1962; Spoormaker et al., 2011). This has been termed 'third-interval omission response' (TOR) or offset SCR'(skin conductance response)', and possibly reflects "surprise" or "relief" upon unexpected omission of the aversive US (Grings et al., 1962; Rescorla and Wagner, 1972; Spoormaker et al., 2011). In appetitive conditioning, measuring skin conductance responses during an expectancy mismatch (e.g., during extinction) could provide an additional measure of learning, possibly reflecting surprise, or frustration/ disappointment, about the non-occurrence of the US (Amsel, 1992; Papini and Dudley, 1992; Spoormaker et al., 2011).

Conditioned responses (including skin conductance) are likely not solely based on physical pairings between a CS and a US. Studies have shown that contingency instructions can have a big impact on responding as well. For example, verbal instructions about the CS-US contingency (e.g., that the CS + predicts a shock) can establish conditioned fear responses in the absence of actual CS-US pairings (e.g., Cook and Harris, 1937; Raes et al., 2014), and information suggesting a reversal of CS-US contingencies after conditioning (e.g., informing participants that the $\mathrm{CS}+$ is no longer followed by a shock) can reverse fear responses (e.g., Cook and Harris, 1937; Mertens and De Houwer, 2016). In many conditioning studies, contingency instructions are provided prior to acquisition, guiding a participant's attention towards the CS-US relationship (e.g., "one of these boxes will sometimes contain something to eat, whereas the other box will never contain anything"). This is done because US expectancies are likely necessary for the development of conditioned (appetitive) responses (Hogarth and Duka, 2005; Lovibond and Shanks, 2002; van den Akker et al., 2013). The precise wording of the contingency instruction might however impact subsequent learning. Specifically, using an ambiguous contingency instruction like "the box will sometimes contain chocolate" (which may be used to account for the fact that the stimulus is not followed by the US during extinction) could result in a pattern of responding similar to that induced by a partial reinforcement schedule, in which the CS-US contingency is $<100 \%$, thereby leading to an attenuated CR during acquisition (e.g., interfering with a successful acquisition of differential skin conductance responses; Dunsmoor et al., 2007), and a slowed extinction (i.e., the partial reinforcement extinction effect; e.g., van den Akker et al., 2014). In the present study, we investigated the effects of a subtle difference in the wording of contingency instructions on conditioning by omitting the word sometimes in one condition.

The primary aim of the present study was to examine whether skin conductance can be used as a measure of conditioned responding in a differential appetitive conditioning paradigm, and to examine which time window provides the most sensitive measure for differential responding - after CS onset (FIR), right before the US is imminent (SIR), or after CS offset (TOR). In addition, the influence of an ambiguous contingency instruction (either including the word sometimes or not) on conditioned responses (US expectancies, desires for chocolate, CS evaluations, and skin conductance) was examined. It was expected that skin conductance would be heightened in response to CS + vs. CS trials after acquisition, and especially in the time window when the US was imminent. It was also hypothesized that an US omission response in $\mathrm{CS}+$ vs. CS - trials would occur when the US was unexpectedly not provided, particularly in early extinction when US omission would be most surprising. Finally, it was expected that relatively ambiguous instructions (ambiguous condition) would attenuate both the acquisition and extinction of conditioned responses, compared with a condition in which the word "sometimes" was omitted (non-ambiguous condition).

\section{Methods and materials}

\subsection{Participants}

Sixty-four participants took part in the study. Of these, four participants were excluded: three because they were not aware of the contingency between the CS and US, and one due to technical errors. These participants were replaced by four additional participants to ensure full counterbalancing. Participants were eligible to participate in the study if they were undergraduate female students, right-handed, aged between 17 and 25 years, and had indicated to like chocolate. It was ensured that none of the participants had previously participated in an appetitive conditioning study. Only females were included to reduce variability in responding. All participants were instructed to have a small meal (such as a sandwich) two hours prior to participation and to refrain from calorie intake thereafter. As a cover story, participants were told the study was about attention and taste perception. Participants received either a monetary reward $(€ 7,50)$ or course credit for participation. The study was approved by the local ethical committee.

\subsection{Stimuli}

Two geometrical shapes [a blue square ( $9.3 \mathrm{~cm}$ wide) and a yellow circle ( $10.4 \mathrm{~cm}$ in diameter)] were used as conditioned stimuli. These were displayed on a computer screen in front of the participant. Which shape served as CS + and CS - was counterbalanced between participants. A small piece of Belgian milk chocolate (approximately 1.3-1.5 g, Rousseau chocolate) placed in a small cup functioned as US.

\subsection{Measures}

Skin conductance: Electrodermal activity was recorded using $\mathrm{Ag}$ / $\mathrm{AgCl}$ electrodes $(8 \mathrm{~mm})$ which were attached to the volar surfaces of the medial phalanges of the index and middle fingers of the left hand (leaving the right hand to give US expectancy and chocolate desire ratings). The electrodes were filled with isotonic electrode paste $(0.5 \%$ saline in a neutral base). The skin conductance signal was amplified using a BrainAmp ExG device and passed to Brain Vision Recorder 2.0 software (Brain Products, Gilching, Germany). The sampling rate was $500 \mathrm{~Hz}$. 
US expectancy and desire for chocolate: computerized Visual Analogue Scales (VAS) were used to assess expectancy to receive chocolate ('To what extent do you expect to receive chocolate at this moment?') and subjective desire for chocolate ('When looking at this picture, how strong is your desire for chocolate at this moment?'). Ratings were scored from 0 (certainly not expect to receive chocolate/no desire at all) to 100 (certainly expect to receive chocolate/very strong desire).

CS evaluations: Evaluations for the CS + and CS - were assessed using two computerized VAS ('How pleasant do you find this picture?'). Ratings ranged from 0 (not pleasant at all) to 100 (extremely pleasant).

Hunger: To be able to control for possible group differences in hunger, participants filled in a computerized VAS ('How hungry are you at this moment?') ranging from 0 (not hungry at all) to 100 (extremely hungry).

US liking: US liking was assessed using a computerized VAS ('How much did you like the chocolate?') ranging from 0 (did not like it at all) to 100 (liked it very much).

\subsection{Design and procedure}

A between-subjects design was used to test the effects of ambiguous vs. non-ambiguous contingency instructions during an acquisition and extinction phase.

Participants were individually seen between 10:45 AM and 6 PM. After arrival, participants were seated at a table, in front of a computer screen. The participant was informed that two electrodes would be attached to her fingers, but that these would not be painful. After giving informed consent, participants were explained how to fill in a VAS. Next, the electrodes were attached to the participant's left hand, and the experimenter explained that the participant would sometimes receive something to eat. The participant was instructed to sit still and keep her left hand still throughout the procedure, while using her right hand to pick up the food and to answer VAS. Next, participants were shown the two geometrical shapes and, depending on the participant's (randomly assigned) condition, she received one of two verbal instructions. In the ambiguous condition, the participant was instructed that after seeing one of the two shapes, she would sometimes receive something to eat. After seeing the other shape, she would never receive anything to eat. Participants were asked to repeat this information once. In the nonambiguous condition, the word "sometimes" was simply omitted. Next, the computer screen was turned on, and the participant completed a hunger VAS. After this, the conditioning procedure started, which was similar for all participants (except for trial order, depending on randomization and counterbalancing, see below).

During acquisition, participants received five CS + trials $(100 \%$ reinforcement) and five CS - trials (see below). Immediately following acquisition the extinction phase started (i.e., there was no indication that contingencies would change prior to extinction), consisting of twelve CS + (no US) and twelve CS - trials. Trials were presented in a semi-randomized order, with no more than two consecutive trials being of the same trial type. Whether extinction started with a CS + or CS trial was counterbalanced across participants. Trial sequences were similar to prior studies to allow concurrent measurement of expectancy and desire VASs (e.g., van den Akker et al., 2016).

A trial proceeded as follows: participants were shown one of the shapes (CS + or CS -) on the computer screen for $10 \mathrm{~s}$, accompanied by the instruction to look at the picture (see Fig. 1). Next, an expectancy VAS appeared below the CS. The trial proceeded when participants clicked a button indicating they had finished filling in the question. After a two-second delay, the desire-for-chocolate VAS was presented. After the participant had completed this question, the VAS disappeared, and the CS remained present for another three seconds. During this period, in case of a CS + trial, the US was placed in front of the participant for consumption. After the three seconds, the CS disappeared, and the inter-trial interval started (ranging from 17 to $23 \mathrm{~s}$ ). After this, the next trial started. Online markers were used to note when a participant took a deep breath, moved, or talked, to be able to remove any skin conductance responses caused by these actions.

After completion of both the acquisition and extinction procedure, participants were presented with the two shapes and completed CS evaluation VASs. Next, they completed a US liking VAS, indicated when they had last eaten, wrote down their suspicions about the study's hypothesis, and the participant's age and study year were assessed. Finally, their height and weight were measured.

\subsection{Data reduction and response definition}

Ledalab V3.4.8 was used for preprocessing and for extraction of skin conductance data (Benedek and Kaernbach, 2010). The data were first downsampled to $10 \mathrm{~Hz}$ (by averaging every 50 samples), and artifacts were manually identified and corrected using a spline interpolation. The data were smoothed by means of convolution with a Hanning window, and continuous decomposition analysis (CDA) was used to obtain skin conductance responses. CDA uses deconvolution to decompose the skin conductance data into its tonic and phasic components, resulting in phasic activity with a zero baseline. CDA is especially advantageous for analysis of overlapping skin conductance responses (i.e., superposition effects), and has been used before for analyzing (fear) conditioning data (e.g., Baeuchl et al., 2015; Cacciaglia et al., 2013; Ebrahimi et al., 2017; Winkelmann et al., 2016). As the dependent variable, the sum of all reconvolved SCR amplitudes with onsets within a time window was used (AmpSum). A minimum response amplitude criterion of 0.01 microSiemens was used. Responses were discarded and replaced by the overall individual mean when they were directly preceded by the participant sighing, talking, or otherwise moving (e.g., Culver et al., 2015), or when no responses were recorded due to technical issues $(1.34 \%$ of all responses; ambiguous CS $+1.22 \%$; CS - $0.61 \%$; non-ambiguous CS + $1.83 \%$; CS - 1.70\%; analyses revealed no significant differences across the conditions in discarded responses, smallest $p=0.16$; Weike et al., 2007). The data were rangecorrected by dividing each skin conductance score by the participant's individual maximal conditioned response (e.g., Cacciaglia et al., 2013), and normalized using a square root transformation.

Three time windows were analyzed based on prior research and visual inspection of the data (Boucsein, 2012; Prokasy and Ebel, 1967; see Fig. 1):

First-interval response (FIR): FIR magnitudes were measured in a time window spanning from 1 to 4 following CS onset.

Second-interval response (SIR): In previous studies using a relatively long delay between CS onset and the US, a 5 s-time window before US delivery has been examined, yielding a more sensitive measure of differential responding (Lovibond et al., 2008). In the current study, a time
CS presentation or

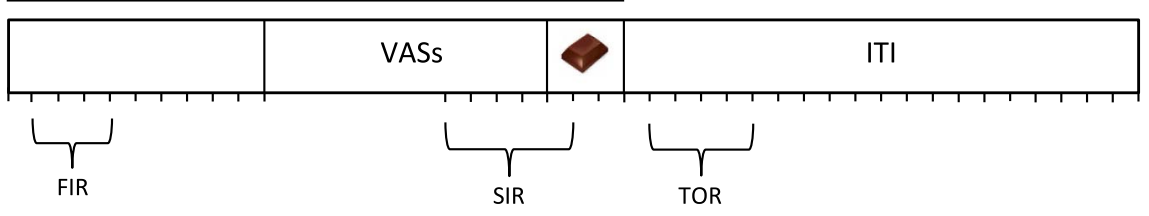

Fig. 1. Overview of a conditioning trial and the three examined time windows. "VASs" indicate administration of the US expectancy and desires VASs. ITI is the inter-trial interval. Each small line reflects one second in the conditioning trial. Chocolate (the US) was given on CS + trials during acquisition only. FIR (first-interval response), SIR (second-interval response), and TOR (third-interval omission response) represent the three time windows during which responses were analyzed. 
window was analyzed spanning from $4 \mathrm{~s}$ before US occurrence to $1 \mathrm{~s}$ after. Note that although this window includes a portion of the US period ( $1 \mathrm{~s})$, it is not contaminated by US occurrence due to the slowness of the skin conductance signal.

Third-interval omission response (TOR): To assess whether skin conductance responses were increased at CS + vs. CS - offset, a time window was analyzed spanning from 1 to $5 \mathrm{~s}$ after stimulus offset. This time window was only examined during extinction (i.e., when no further USs were provided).

\subsection{Statistical analyses}

Differential acquisition and extinction of desire for chocolate, US expectancy, and skin conductance over trials and across conditions were analyzed using repeated-measures ANOVAs for each phase of the experiment (acquisition and extinction), and, for the skin conductance data, for each time window (FIR, SIR, and TOR). This resulted in 2 (Condition: ambiguous vs. non-ambiguous) $\times 2$ (CS-type: CS + vs. CS -) $\times 5 / 12$ (Acquisition Trial/Extinction Trial) repeated-measures ANOVAs, including CS-type (CS) and Trial (T) as within-subjects factors and Condition (C) as between-subjects factor. For all measures (desire for chocolate, US expectancy, skin conductance responses, and CS evaluations), differential responding on the last acquisition trial, the first extinction trial, and the last extinction was additionally analyzed (when applicable) using 2 (CS-type: CS + vs. CS - ) $\times 2$ (Condition: ambiguous vs. non-ambiguous) repeated-measures ANOVAs. When appropriate, significant interactions with condition were followed up by examining responses within each condition. Greenhouse-Geisser epsilon corrections are reported for repeated measures ANOVAs when the assumption of sphericity was violated.

\section{Results}

\subsection{Participant characteristics}

Participant characteristics are provided in Table 1 . Since the conditions differed in BMI, centered BMI score was included as covariate in the analyses. Because this did not change the pattern of results, in the reported analyses, BMI was not included. Finally, none of the participants correctly guessed the hypothesis of the study.

\subsection{US expectancies and desires for chocolate}

Participants acquired US expectancies when presented with the CS + vs. CS - , as evidenced by a significant CS $\times$ T interaction, $F(2.30$, $142.63)=82.54, p<0.001, \eta_{\mathrm{p}}{ }^{2}=0.57$. Conditions differed in the course of acquisition, $\mathrm{CS} \times \mathrm{T} \times \mathrm{C}, F(2.30,142.63)=3.07, p=0.04$, $\eta_{\mathrm{p}}{ }^{2}=0.05$ (see Fig. 2), which seemed to be due to greater differential US expectancies in the ambiguous condition already on the first acquisition trial, $F(1,62)=6.11, p=0.02, \eta_{\mathrm{p}}{ }^{2}=0.09 .{ }^{1}$ On the last acquisition trial, a significant differentiation in US expectancies was present, $F(1,62)=1308.71, p<0.001, \eta_{\mathrm{p}}{ }^{2}=0.96$, and equally so for both conditions, $F<1$.

The acquired differentiation was still present on extinction trial $1, F$ $(1,62)=667.49, p<0.001, \eta_{\mathrm{p}}{ }^{2}=0.92$, with no differences across conditions, $F<1$. Differential US expectancies extinguished, CS $\times \mathrm{T}$, $F(4.49,278.52)=86.71, p<0.001, \eta_{\mathrm{p}}^{2}=0.58$ (see Fig. 2). Although

\footnotetext{
${ }^{1}$ Closer inspection of the data suggested that these baseline differences may have been caused by random group differences in the type of trial that participants received first during acquisition. Twenty participants in the ambiguous condition received the CS + first, whereas fifteen participants in the non-ambiguous condition did. Tests showed that receiving the CS + first had a strong positive effect on the differentiation on trial $1, F(1$, $62)=25.59, p<0.001, \eta_{\mathrm{p}}{ }^{2}=0.29$, and when adding the type of first trial (CS + or $\mathrm{CS}-$ ) as covariate in the analysis the CS $\times \mathrm{T} \times \mathrm{C}$ interaction became non-significant, $F<1$.
}

Table 1

Participants characteristics per condition; means with standard deviations in parentheses.

\begin{tabular}{lllll}
\hline $\mathrm{n}$ & Ambiguous & Non-ambiguous & $t(62)$ & $p$ \\
\cline { 2 - 5 } & 32 & 32 & & \\
\hline Age & $19.56(1.27)$ & $19.56(1.72)$ & 0.00 & $>0.99$ \\
Baseline hunger & $54.16(20.05)$ & $50.06(22.97)$ & 0.76 & 0.45 \\
US liking & $73.19(21.19)$ & $75.13(14.67)$ & 0.43 & 0.67 \\
BMI & $22.52(3.45)$ & $24.91(5.32)$ & 2.14 & 0.04 \\
\hline
\end{tabular}

the course of extinction did not differ across conditions, $\mathrm{CS} \times \mathrm{T} \times \mathrm{C}, F$ $(4.49,278.52)=1.37, p=0.24, \eta_{\mathrm{p}}^{2}=0.02$, on the last extinction trial, differential expectancies were larger in the ambiguous vs. nonambiguous condition, $F(1,62)=10.83, p=0.002, \eta_{\mathrm{p}}{ }^{2}=0.15$. Followup analyses suggested that on the last extinction trial, expectancies had extinguished in the non-ambiguous, $F(1,31)=1.99, p=0.17$, $\eta_{\mathrm{p}}{ }^{2}=0.06$, but not in the ambiguous condition, $F(1,31)=27.99$, $p<0.001, \eta_{\mathrm{p}}^{2}=0.47$. This suggests that, in line with expectations, the ambiguous instruction slowed extinction.

A differential desire for chocolate was acquired, $\mathrm{CS} \times \mathrm{T}, F(2.41$, $149.58)=15.27, p<0.001, \eta_{\mathrm{p}}{ }^{2}=0.20$, resulting in a significantly larger desire in response to the CS + vs CS - on the last acquisition trial, $F(1,62)=49.89, p<0.001, \eta_{\mathrm{p}}{ }^{2}=0.45$ (see Fig. 2). Conditions did not differ in the course of acquisition nor in final acquisition levels, Fs $<1$. Differential desires were still present on the first extinction trial, $F(1,62)=49.93, p<0.001, \eta_{\mathrm{p}}{ }^{2}=0.45$, with no differences across conditions, $F(1,62)=1.71, p=0.20, \eta_{\mathrm{p}}{ }^{2}=0.03$. Chocolate desires extinguished to some extent, $\mathrm{CS} \times \mathrm{T}, F(7.03,435.64)=2.41$, $p=0.02, \eta_{\mathrm{p}}{ }^{2}=0.04$ (see Fig. 2). On the last extinction trial, a differentiation between the CS + and $\mathrm{CS}-$ was still present, $F(1,62)$ $=24.11, p<0.001, \eta_{\mathrm{p}}{ }^{2}=0.28$. The course of extinction and final extinction levels were similar for the conditions, Fs $<1$.

In sum, differential US expectancies and chocolate desires were successfully acquired, and they extinguished to some extent. This overall pattern is similar to findings of previous studies. Further, our manipulation affected the extinction of US expectancies: extinction was less complete in the ambiguous vs. non-ambiguous condition.

\subsection{CS evaluations}

After extinction, evaluations for the CS + were significantly higher than for the CS $-, F(1,62)=25.64, p<0.001, \eta_{\mathrm{p}}{ }^{2}=0.29$, with no differences across conditions, $F<1$ (ambiguous: $\mathrm{CS}+\mathrm{M}=55.03$, $\mathrm{SD}=16.38 ; \mathrm{CS}-\mathrm{M}=37.63, \mathrm{SD}=17.96$; non-ambiguous: $\mathrm{CS}+$ $52.78, \mathrm{SD}=20.80$; $\mathrm{CS}-\mathrm{M}=33.94, \mathrm{SD}=21.75$ ).

\subsection{Skin conductance responses}

FIR: FIR magnitudes did not increase over time in response to CS + vs. CS - onset (CS $\times \mathrm{T}), F<1$, with no differences across conditions, $\mathrm{CS} \times \mathrm{T} \times \mathrm{C}, F(3.29,203.87)=1.50, p=0.21, \eta_{\mathrm{p}}{ }^{2}=0.02$. In line with this, no significant differentiations were present on the last acquisition trial or on the first extinction trial, $F s<1$, as well as no interactions with condition, $F \mathrm{~s}<1$ (data not shown).

SIR: The CS + vs. CS - differentiation did not change over time, $F$ $(3.46,214.42)=1.14, p=0.34, \eta_{p}{ }^{2}=0.02$, irrespective of condition, $F<1$. However, and in line with visual inspection of the data, there was a main effect of CS-type, $F(1,62)=4.61, p=0.036, \eta_{\mathrm{p}}{ }^{2}=0.07$, indicating larger responses to the CS + vs. CS - , and a significant CS $\times$ C interaction, $F(1,62)=4.30, p=0.04, \eta_{\mathrm{p}}{ }^{2}=0.07$ (see Fig. 3). Follow-up analyses within each condition suggested overall increased skin conductance responses to the CS + in the ambiguous condition, $F$ $(1,31)=10.08, p=0.003, \eta_{\mathrm{p}}{ }^{2}=0.25$, but not in the non-ambiguous condition, $F<1$. In line with this, on the last acquisition trial, the ambiguous condition showed a significant CS + vs. CS - 


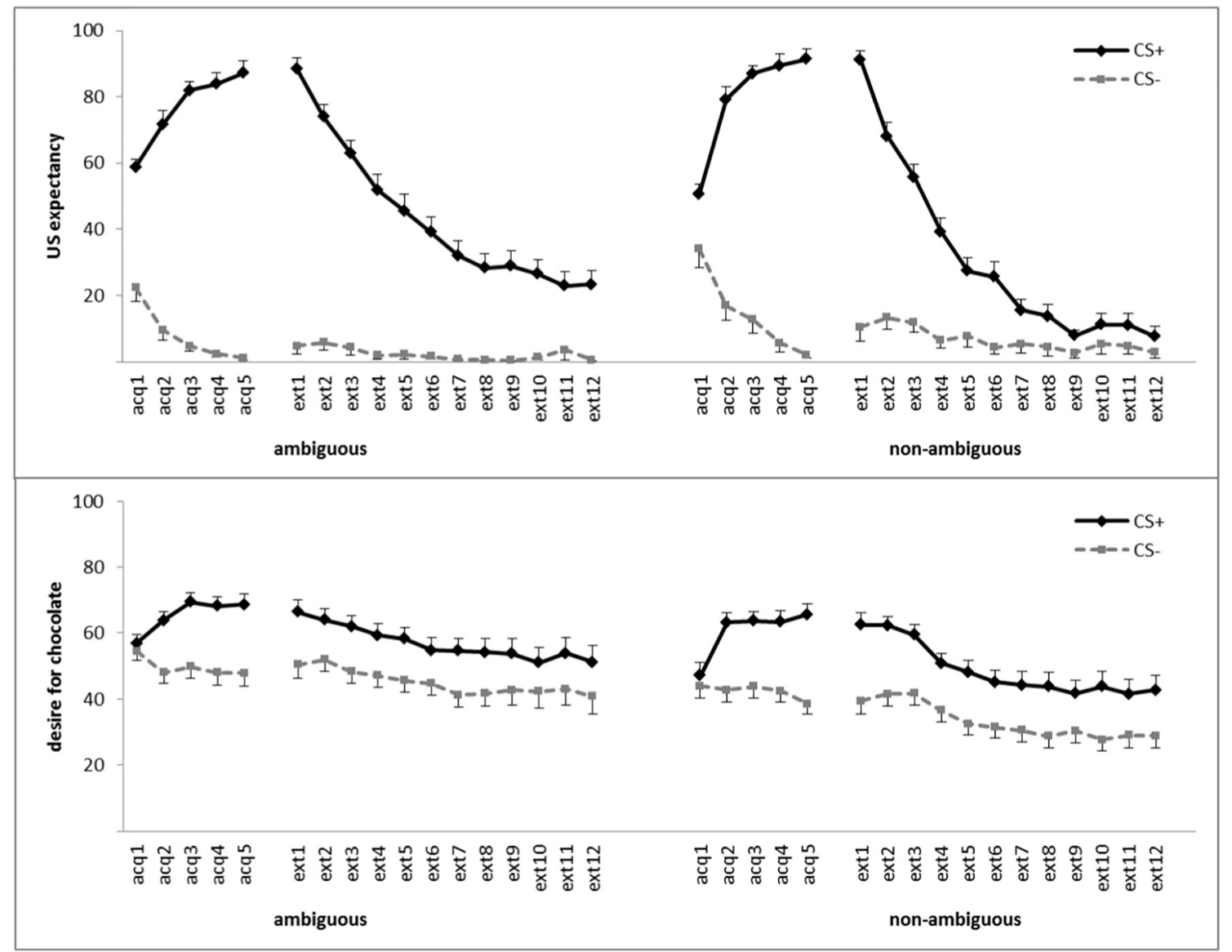

Fig. 2. Mean US expectancy and desire for chocolate ratings ( \pm SEM), per condition, CS-type, and trial. "acq" refers to acquisition (5 trials); "ext" refers to extinction (12 trials).

differentiation, $F(1,31)=4.25, p=0.048, \eta_{\mathrm{p}}{ }^{2}=0.12$, whereas the non-ambiguous condition did not, $F<1$ (although the overall CS $\times \mathrm{C}$ interaction on this trial did not reach significance, $F(1,62)=1.46$, $p=0.23, \eta_{\mathrm{p}}^{2}=0.02$ ).

On the first extinction trial, SIR magnitudes differed significantly between conditions, $F(1,62)=5.91, p=0.018, \eta_{\mathrm{p}}^{2}=0.09$ (main effect of CS: $\left.F(1,62)=3.18, p=0.08, \eta_{\mathrm{p}}{ }^{2}=0.05\right)$. Follow-up analyses indicated a differentiation in the ambiguous, $F(1,31)=9.47$, $p=0.004, \eta_{\mathrm{p}}{ }^{2}=0.23$, but not in the non-ambiguous condition, $F<1$ (see Fig. 3). The reduction in differential skin conductance scores in the ambiguous condition over the course of extinction was not significant, CS x T, $F=1.10, n s$.

TOR: a TOR to the CS + (vs. CS - ) was found on the first extinction trial, $F(1,62)=14.83, p<0.001, \eta_{\mathrm{p}}^{2}=0.19$, with no significant differences across conditions, $F=1.03$, $n s$ (see Fig. 3). Extinction of the omission response was marginally significant, $\mathrm{CS} \times \mathrm{T}, F(8.63,535.05)$ $=1.75, p=0.08, \eta_{\mathrm{p}}{ }^{2}=0.03$, and there was no significant $\mathrm{CS}+\mathrm{vs}$. CS - differentiation on the last extinction trial, $F(1,62)=2.73$, $p=0.10, \eta_{\mathrm{p}}{ }^{2}=0.04$. The course of extinction and final extinction levels did not differ across conditions, $F s<1$.

In sum, the results suggest that the time window shortly before US occurrence (SIR) and the time window after expected US occurrence in extinction (TOR), but not the time window right after CS onset (FIR), provide sensitive time windows to detect differences between the two CS-types. Evidence for increased SIR magnitudes to the CS + was only found in participants who had received ambiguous instructions about the CS-US contingency - though the change in differential responding over the course of acquisition did not reach significance. Furthermore, acquired differential skin conductance responses extinguished rapidly when CS-US pairings were discontinued during extinction.

\section{Discussion}

The aims of the present study were to 1) examine whether skin conductance is a measure of differential responding in appetitive conditioning, and if so, which time window is most sensitive to distinguish between the CS + and CS - , and 2) investigate whether inclusion of the ambiguous word sometimes in a contingency instruction attenuates acquisition and extinction. Results suggested differential skin conductance responses when the US was imminent (i.e., SIR), though only for participants who received an ambiguous contingency instruction. An US omission response (i.e., TOR) was also found. In contrast, no differential responses were found for the time window following CS onset (i.e., FIR). Finally, the ambiguous contingency instruction was related to a worse extinction of US expectancies.

These findings indicate that the skin conductance response can function as a sensitive measure of differential responding in appetitive conditioning involving food rewards: evidence for acquisition of differential responses was found in an anticipatory time window when the US was imminent (though the overall change in differential responding over the course of acquisition did not reach significance), and an US omission response was present when the US unexpectedly did not occur in early extinction. The finding that the pre-US vs. CS onset time window is better able to distinguish $\mathrm{CS}+$ and $\mathrm{CS}-$ trials in case of longer CS-US intervals seems in line with unpublished pilot data of previous work in fear conditioning (Lovibond et al., 2008). It is likely that participants learn about the temporal delay between CS onset and the occurrence of the US, and as a result show anticipatory skin conductance responses shortly before the US is expected. Further, the omission response that was found may reflect surprise or frustration/ disappointment when the US unexpectedly did not occur during 


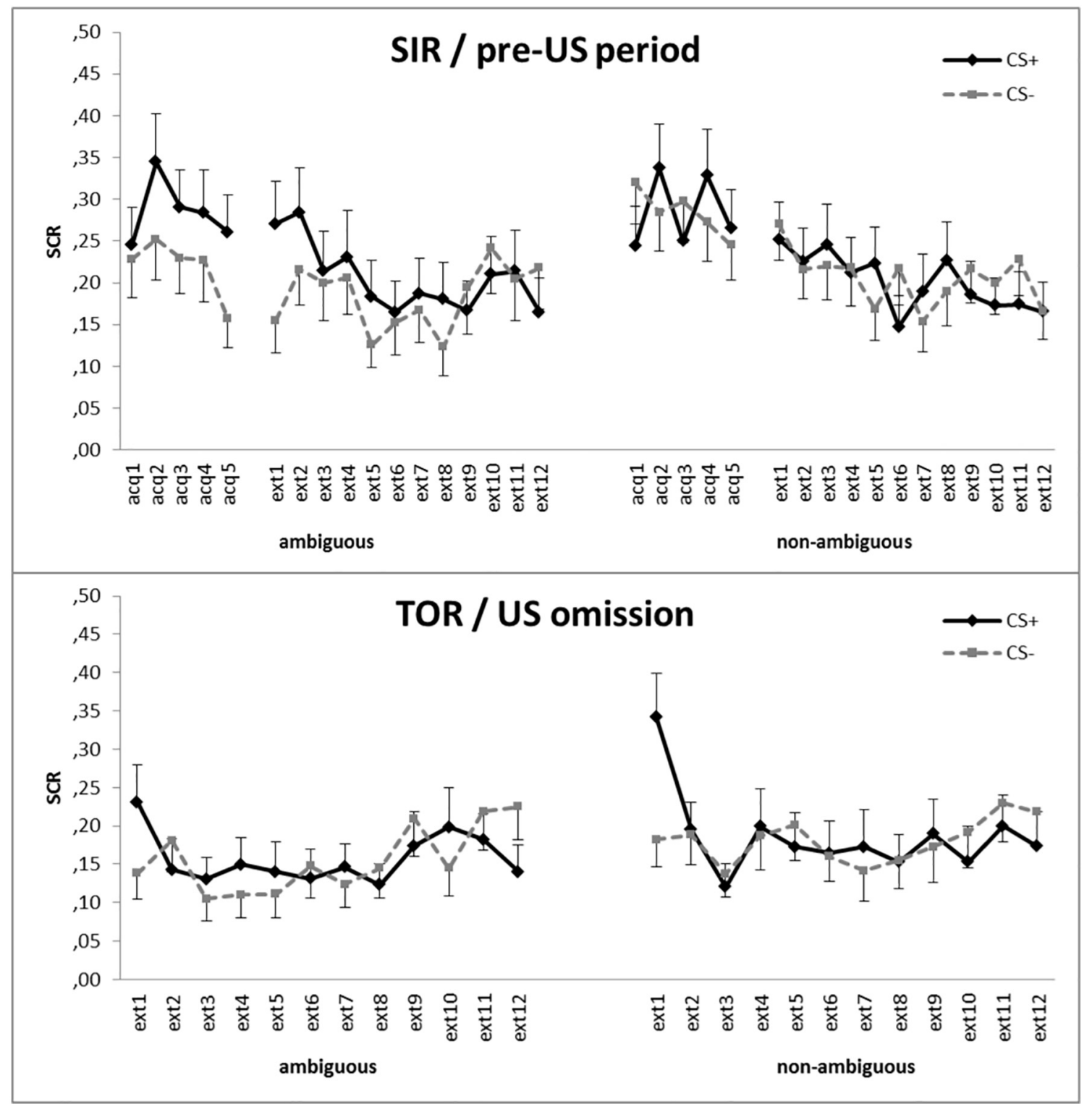

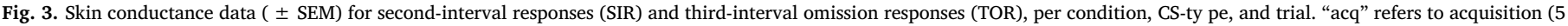
trials); "ext" refers to extinction (12 trials). "SCR" represents the mean range-corrected and square root transformed sum of amplitudes within the response window.

extinction (e.g., Amsel, 1992; Papini and Dudley, 1992; Spoormaker et al., 2011). Visual inspection of the data indicated that this response was only present on the first extinction trial, suggesting that it may only occur in appetitive conditioning when non-occurrence of the US is very surprising. Thus, future studies that use a similar appetitive conditioning paradigm may wish to 1) examine skin conductance in the pre-US period, 2) take into account ambiguity of the CS-US relationship, and 3) examine the US omission response.

The unexpected finding that an acquisition of differential skin conductance responses was only found in participants who received ambiguous contingency instructions is interesting and merits further discussion. This finding suggests that anticipatory skin conductance responses can be conditioned to appetitive stimuli, however, it also gives rise to the question what this response reflects (Boddez et al., 2012; Domjan, 2005; Öhman, 1974). Research on fear conditioning has shown that anticipatory skin conductance responding may primarily index US expectancies (Hamm and Weike, 2005; Sevenster et al., 2012), and the current finding that US expectancies (but not skin conductance responses) were acquired in both conditions does not seem in line with this notion. However, it is also well-known that electrodermal responding is sensitive to a multitude of psychological processes including attention and cognitive effort (Critchley, 2002), and it has been proposed that a "call for processing resources" is elicited in response to a stimulus when it is identified as "significant" and further processing is required, heightening electrodermal responding (Filion et al., 1991; Lipp et al., 1994; Lipp and Vaitl, 1990; Öhman et al., 1986; Pearce and Hall, 1980). For participants in the ambiguous condition, the unclear CS-US contingency might have resulted in the CS + being perceived as more "significant" and in need of controlled processing, whereas for participants in the non-ambiguous condition, the outcome seemed certain and no additional processing was required (Öhman et al., 1986; Pearce and Hall, 1980). This could have resulted in differential skin conductance responses only in the ambiguous condition. Interestingly, there is also some prior evidence that such effects of uncertainty can be specific to appetitive situations. In one study, participants completed either an appetitive or aversive conditioning task (using money or a blast of white noise as US, respectively), including CSs that signaled varying US probabilities $(100 \%, 50 \%$, or $0 \%$; Austin and Duka, 2010; but see Austin and Duka, 2012). Attention to the CSs was measured using eye-tracking. It was found that during aversive conditioning 
attention was higher to stimuli predicting the US as outcome certainty increased (see also Davies and Craske, 2015; Dunsmoor et al., 2007; Grupe and Nitschke, 2011). In contrast, during appetitive conditioning, attention was highest to a stimulus signaling uncertainty (50\% contingency). Although skin conductance responses in this study did not show the same pattern, these findings might be consistent with our current data - assuming that attentional mechanisms were involved in the differential responding in the ambiguous condition. In sum, the current data point towards interesting modulations in anticipatory skin conductance responses to appetitive CSs induced by contingency instruction ambiguity, but additional studies are needed to investigate what exact processes may underlie these findings and if and how they differ for appetitive vs. aversive conditioning.

Finally, apart from its effects on anticipatory skin conductance responses, contingency instruction ambiguity was related to a worse extinction of US expectancies. This might be best explained by a verbally induced partial reinforcement extinction effect (Haselgrove et al., 2004; van den Akker et al., 2014). This finding, combined with the additional effects of contingency instruction ambiguity on skin conductance responses in the present study, suggests that subtle changes in contingency instructions can have a substantial impact on responding. Researchers therefore may wish to take into account subtleties in their exact framing of contingency instructions when designing their studies.

In sum, we found evidence for skin conductance to be a sensitive measure of differential responding in appetitive conditioning involving food rewards in two time windows: when the US was imminent, and during unexpected omission of the US in early extinction. Interestingly however, differential anticipatory responses were only found for participants who had received an ambiguous contingency instruction. This could indicate a call for additional processing resources, and suggests that the sensitivity of this anticipatory measure might be dependent on the specific task context. Apart from their effects on skin conductance, verbal contingency instructions also affected US expectancies - as expected, ambiguous instructions slowed their extinction. Future (appetitive) conditioning studies may wish to further examine and/or take into account effects of contingency instruction ambiguity.

\section{Conflict of interest}

The authors declare no conflict of interest.

\section{Acknowledgments}

This study is part of a project that is financed by the Netherlands Organisation for Scientific Research (NWO): Vici Grant 453.10.006, awarded to Anita Jansen.

The authors would like to thank Bram Vervliet and Fren Smulders for valuable comments on the design of the study and the analyses, and Johan Gielissen and Jacco Ronner for technical support.

\section{References}

van den Akker, K., Jansen, A., Frentz, F., Havermans, R.C., 2013. Impulsivity makes more susceptible to overeating after contextual appetitive conditioning. Appetite 70 , 73-80. http://dx.doi.org/10.1016/j.appet.2013.06.092.

van den Akker, K., Havermans, R.C., Bouton, M.E., Jansen, A., 2014. How partial reinforcement of food cues affects the extinction and reacquisition of appetitive responses. A new model for dieting success? Appetite 81, 242-252. http://dx.doi.org/ 10.1016/j.appet.2014.06.024.

van den Akker, K., Havermans, R.C., Jansen, A., 2015. Effects of occasional reinforced trials during extinction on the reacquisition of conditioned responses to food cues. J. Behav. Ther. Exp. Psychiatry 48, 50-58. http://dx.doi.org/10.1016/j.jbtep.2015.02. 001.

van den Akker, K., van den Broek, M., Havermans, R.C., Jansen, A., 2016. Violation of eating expectancies does not reduce conditioned desires for chocolate. Appetite 100, 10-17. http://dx.doi.org/10.1016/j.appet.2016.02.004.

Amsel, A., 1992. Frustration theory - many years later. Psychol. Bull. 112, 396-399.

Andreatta, M., Pauli, P., 2015. Appetitive vs. Aversive conditioning in humans. Front.

Behav. Neurosci. 9, 128. http://dx.doi.org/10.3389/fnbeh.2015.00128.

Austin, A.J., Duka, T., 2010. Mechanisms of attention for appetitive and aversive outcomes in Pavlovian conditioning. Behav. Brain Res. 213, 19-26. http://dx.doi. org/10.1016/j.bbr.2010.04.019.

Austin, A.J., Duka, T., 2012. Mechanisms of attention to conditioned stimuli predictive of a cigarette outcome. Behav. Brain Res. 232, 183-189. http://dx.doi.org/10.1016/j. bbr.2012.04.009.

Baeuchl, C., Meyer, P., Hoppstädter, M., Diener, C., Flor, H., 2015. Contextual fear conditioning in humans using feature-identical contexts. Neurobiol. Learn. Mem. 121, 1-11. http://dx.doi.org/10.1016/j.nlm.2015.03.001.

Beckers, T., Krypotos, A.-M., Boddez, Y., Effting, M., Kindt, M., 2013. What's wrong with fear conditioning? Biol. Psychol. 92 (1), 90-96. http://dx.doi.org/10.1016/j. biopsycho.2011.12.015.

Benedek, M., Kaernbach, C., 2010. A continuous measure of phasic electrodermal activity. J. Neurosci. Methods 190 (1), 80-91. http://dx.doi.org/10.1016/j.jneumeth.2010. 04.028.

Blechert, J., Testa, G., Georgii, C., Klimesch, W., Wilhelm, F.H., 2016. The Pavlovian craver: neural and experiential correlates of single trial naturalistic food conditioning in humans. Physiol. Behav. 158, 18-25. http://dx.doi.org/10.1016/j.physbeh.2016. 02.028 .

Boddez, Y., Baeyens, F., Luyten, L., Vansteenwegen, D., Hermans, D., Beckers, T., 2012. Rating data are underrated: validity of US expectancy in human fear conditioning. J. Behav. Ther. Exp. Psychiatry 44, 201-206. http://dx.doi.org/10.1016/j.jbtep.2012. 08.003.

Bongers, P., van den Akker, K., Havermans, R., Jansen, A., 2015. Emotional eating and Pavlovian learning: does negative mood facilitate appetitive conditioning? Appetite 89, 226-236. http://dx.doi.org/10.1016/j.appet.2015.02.018.

Boswell, R.G., Kober, H., 2016. Food cue reactivity and craving predict eating and weight gain: a meta-analytic review. Obes. Rev. 17 (2), 159-177. http://dx.doi.org/10. 1111/obr.12354.

Boucsein, W., 2012. Electrodermal Activity. Springer Science \& Business Media.

Bouton, M.E., 2011. Learning and the persistence of appetite: extinction and the motivatin to eat and overeat. Physiol. Behav. 103, 51-58. http://dx.doi.org/10.1016/j. physbeh.2010.11.025.

Cacciaglia, R., Nees, F., Pohlack, S.T., Ruttorf, M., Winkelmann, T., Witt, S.H., ... Flor, H., 2013. A risk variant for alcoholism in the NMDA receptor affects amygdala activity during fear conditioning in humans. Biol. Psychol. 94, 74-81. http://dx.doi.org/10. 1016/j.biopsycho.2013.05.006.

Carter, B.L., Tiffany, S.T., 2001. The cue reactivity paradigm: the effects of cigarette availability on cue reactivity in smokers. Exp. Clin. Psychopharmacol. 9, 183-190.

Cook, S.W., Harris, R.E., 1937. The verbal conditioning of the galvanic skin reflex. J. Exp. Psychol. 21, 202-210. http://dx.doi.org/10.1037/h0063197.

Critchley, H.D., 2002. Book review: electrodermal responses: what happens in the brain Neuroscientist 8 (2), 132-142. http://dx.doi.org/10.1177/107385840200800209.

Culver, N.C., Vervliet, B., Craske, M.G., 2015. Compound extinction. Using the RescorlaWagner model to maximize exposure therapy effects for anxiety disorders. Clin. Psychol. Sci. 3, 335-348. http://dx.doi.org/10.1177/2167702614542103.

Davies, C.D., Craske, M.G., 2015. Psychophysiological responses to unpredictable threat: effects of cue and temporal unpredictability. Emotion 15 (2), 195-200. http://dx.doi. org/10.1037/emo0000038.

Dawson, M.E., Schell, A.M., Filion, D., 2007. The electrodermal system. In: Cacioppo, J.T. Tassinary, L.G., Berntson, G.G. (Eds.), Handbook of Psychophysiology. Cambridge University Press.

Delamater, A.R., Oakeshott, S., 2007. Learning about multiple attributes of reward in Pavlovian conditioning. Ann. N. Y. Acad. Sci. 1104 (1), 1-20. http://dx.doi.org/10. 1196/annals.1390.008.

Domjan, M., 2005. Pavlovian conditioning: a fucntional perspective. Annu. Rev. Psychol. 56, 179-206. http://dx.doi.org/10.1146/annurev.psych.55.090902.141409.

Dunsmoor, J.E., LaBar, K.S., 2012. Brain activity associated with omission of an aversive event reveals the effects of fear learning and generalization. Neurobiol. Learn. Mem. 97 (3), 301-312. http://dx.doi.org/10.1016/j.nlm.2012.02.003.

Dunsmoor, J.E., Bandettini, P.A., Knight, D.C., 2007. Impact of continuous versus intermittent CS-UCS pairing on human brain activation during Pavlovian fear conditioning. Behav. Neurosci. 121 (4), 635.

Ebrahimi, C., Koch, S.P., Friedel, E., Crespo, I., Fydrich, T., Ströhle, A., ... Schlagenhauf, F., 2017. Combining D-cycloserine with appetitive extinction learning modulates amygdala activity during recall. Neurobiol. Learn. Mem. 142, 209-217. http://dx. doi.org/10.1016/j.nlm.2017.05.008.

Field, M., Duka, T., 2001. Smoking expectancy mediates the conditioned responses to arbitrary smoking cues. Behav. Pharmacol. 12 (3), 183-194. http://dx.doi.org/10. 1097/00008877-200105000-00004.

Filion, D.L., Dawson, M.E., Schell, A.M., Hazlett, E.A., 1991. The relationship between skin conductance orienting and the allocation of processing resources. Psychophysiology 28, 410-424. http://dx.doi.org/10.1111/j.1469-8986.1991. tb00725.x.

Franken, I.H.A., Huijding, J., Nijs, I.M.T., van Strien, J.W., 2011. Electrophysiology of appetitive taste and appetitive taste conditioning in humans. Biol. Psychol. 86 (3), 273-278. http://dx.doi.org/10.1016/j.biopsycho.2010.12.008.

Gawronski, B., Gast, A., De Houwer, J., 2015. Is evaluative conditioning really resistant to extinction? Evidence for changes in evaluative judgements without changes in evaluative representations. Cognit. Emot. 29 (5), 816-830. http://dx.doi.org/10.1080/ 02699931.2014 .947919$.

Glautier, S., Drummond, C., Remington, B., 1994. Alcohol as an unconditioned stimulus in human classical conditioning. Psychopharmacology 116 (3), 360-368. http://dx. doi.org/10.1007/BF02245341.

Grings, W.W., Lockhart, R.A., Dameron, L.E., 1962. Conditioning autonomic responses of mentally subnormal individuals. Psychol. Monogr. 76, 1-35.

Grupe, D.W., Nitschke, J.B., 2011. Uncertainty is associated with biased expectancies and 
heightened responses to aversion. Emotion 11 (2), 413-424. (Washington, D.C.). http://dx.doi.org/10.1037/a0022583.

Hamm, A.O., Weike, A.I., 2005. The neuropsychology of fear learning and fear regulation. Int. J. Psychophysiol. 57 (1), 5-14. http://dx.doi.org/10.1016/j.ijpsycho.2005.01. 006.

Haselgrove, M., Aydin, A., Pearce, J.M., 2004. A partial reinforcement extinction effect despite equal rates of reinforcement during Pavlovian conditioning. J. Exp. Psychol Anim. Behav. Process. 30 (3), 240.

Hogarth, L., Duka, T., 2005. Human nicotine conditioning requires explicit contingency knowledge: is addictive behaviour cognitively mediated? Psychopharmacology 184 (3), 553-566. http://dx.doi.org/10.1007/s00213-005-0150-0.

Jansen, A., 1998. A learning model of binge eating: cue reactivity and cue exposure. Behav. Res. Ther. 36 (3), 257-272. http://dx.doi.org/10.1016/S0005-7967(98) 00055-2.

Jansen, A., Havermans, R.C., Nederkoorn, C., 2011. Cued overeating. In: Preedy, V.R., Watson, R.R., Martin, C.R. (Eds.), Handbook of Behavior, Food and Nutrition. Springer, New York.

Jansen, A., Schyns, G., Bongers, P., van den Akker, K., 2016. From lab to clinic: extinction of cued cravings to reduce overeating. Physiol. Behav. 162, 174-180. http://dx.doi. org/10.1016/j.physbeh.2016.03.018.

Klucken, T., Kruse, O., Wehrum-Osinsky, S., Hennig, J., Schweckendiek, J., Stark, R. 2015. Impact of COMT Val158Met-polymorphism on appetitive conditioning and amygdala/prefrontal effective connectivity. Hum. Brain Mapp. 36 (3), 1093-1101. http://dx.doi.org/10.1002/hbm.22688.

Kruse, O., León, I.T., Stark, R., Klucken, T., 2017. Neural correlates of appetitive extinction in humans. Soc. Cogn. Affect. Neurosci. 12, 106-115. http://dx.doi.org/10. 1093/scan/nsw157.

Lipp, O.V., 2006. Human fear learning: contemporary procedures and measurement. In: Craske, M.G., Hermans, D., Vansteenwegen, D. (Eds.), Fear and learning: From basic processes to clinical implications. American Psychological Association, Washington, DC, pp. 37e52.

Lipp, O.V., Purkis, H.M., 2006. The effects of assessment type on verbal ratings of conditional stimulus valence and contingency judgments: implications for the extinction of evaluative learning. J. Exp. Psychol. Anim. Behav. Process. 32 (4), 431-440. http://dx.doi.org/10.1037/0097-7403.32.4.431.

Lipp, O.V., Vaitl, D., 1990. Reaction time task as unconditional stimulus. Pavlov. J. Biol. Sci. 25 (2), 77-83.

Lipp, O.V., Sheridan, J., Siddle, D.A., 1994. Human blink startle during aversive and nonaversive Pavlovian conditioning. J. Exp. Psychol. Anim. Behav. Process. 20 (4), 380 .

Lovibond, P.F., Shanks, D.R., 2002. The role of awareness in Pavlovian conditioning: empirical evidence and theoretical implications. J. Exp. Psychol. Anim. Behav. Process. 28, 3-26. http://dx.doi.org/10.1037//0097-7403.28.1.3.

Lovibond, P.F., Saunders, J.C., Weidemann, G., Mitchell, C.J., 2008. Evidence for expectancy as a mediator of avoidance and anxiety in a laboratory model of human avoidance learning. Q. J. Exp. Psychol. 61 (8), 1199-1216. http://dx.doi.org/10. 1080/17470210701503229.

Mertens, G., De Houwer, J., 2016. Potentiation of the startle reflex is in line with contingency reversal instructions rather than the conditioning history. Biol. Psychol. 113, 91-99. http://dx.doi.org/10.1016/j.biopsycho.2015.11.014.

Meyer, M.D., Risbrough, V.B., Liang, J., Boutelle, K.N., 2015. Pavlovian conditioning to hedonic food cues in overweight and lean individuals. Appetite 87, 56-61. http://dx. doi.org/10.1016/j.appet.2014.12.002.

Nederkoorn, C., Smulders, F.T.Y., Jansen, A., 2000. Cephalic phase responses, craving and food intake in normal subjects. Appetite 35 (1), 45-55. http://dx.doi.org/10.1006/ appe. 2000.0328

O'Doherty, J.P., Dayan, P., Friston, K., Critchley, H., Dolan, R.J., 2003. Temporal difference models and reward-related learning in the human brain. Neuron 38 (2), 329-337. http://dx.doi.org/10.1016/S0896-6273(03)00169-7.

Ogden, C.L., Carroll, M.D., Kit, B.K., Flegal, K.M., 2014. PRevalence of childhood and adult obesity in the united states, 2011-2012. JAMA 311 (8), 806-814. http://dx.doi. org/10.1001/jama.2014.732.

Öhman, A., 1974. Orienting reactions, expectancy learning, and conditioned responses in electrodermal conditioning with different interstimulus intervals. Biol. Psychol. 1, 189-200.

Öhman, A., Nordby, H., d'Elia, G., 1986. Orienting and schizophrenia: stimulus significance, attention, and distraction in a signaled reaction time task. J. Abnorm. Psychol. 95, 326-334.

Papini, M.R., Dudley, R.T., 1992. Consequences of surprising reward omission. Rev. Gen. Psychol. 1, 175-197.

Pearce, J.M., Hall, G., 1980. A model for Pavlovian learning: variation in the effectiveness of conditioned but not of unconditioned stimuli. Psychol. Rev. 87, 532-552. http:// dx.doi.org/10.1037/0033-295X.87.6.532.

Prokasy, W.F., Ebel, H.C., 1967. Three components of the classically conditioned GSR in human subjects. J. Exp. Psychol. 73 (2), 247.

Prokasy, W.F., Kumpfer, K., 1973. Classical conditioning. In: Electrodermal Activity In Psychological Research, pp. 157-202.

Raes, A.K., De Houwer, J., De Schryver, M., Brass, M., Kalisch, R., 2014. Do CS-US pairings actually matter? A within-subject comparison of instructed fear conditioning with and without actual CS-US pairings. PLoS One 9 (1), e84888.

Rescorla, R.A., Wagner, A.R., 1972. A theory of Pavlovian conditioning: variations in the effectiveness of reinforcement and nonreinforcement. In: Black, A.H., Prokasky, W.F. (Eds.), Classical Conditioning: II. Current Research and Theory. Century-Crofts, New York Appleton, pp. 64-99.

Sevenster, D., Beckers, T., Kindt, M., 2012. Instructed extinction differentially affects the emotional and cognitive expression of associative fear memory. Psychophysiology 49 (10), 1426-1435. http://dx.doi.org/10.1111/j.1469-8986.2012.01450.x.

Spoormaker, V.I., Andrade, K.C., Schröter, M.S., Sturm, A., Goya-Maldonado, R., Sämann, P.G., Czisch, M., 2011. The neural correlates of negative prediction error signaling in human fear conditioning. NeuroImage 54 (3), 2250-2256. http://dx.doi.org/10. 1016/j.neuroimage.2010.09.042.

Swinburn, B., Egger, G., Raza, F., 1999. Dissecting obesogenic environments: the development and application of a framework for identifying and prioritizing environmental interventions for obesity. Prev. Med. 29 (6), 563-570. http://dx.doi.org/10. 1006/pmed.1999.0585.

Van Gucht, D., Vansteenwegen, D., Beckers, T., Van den Bergh, O., 2008a. Return of experimentally induced chocolate craving after extinction in a different context: divergence between craving for and expecting to eat chocolate. Behav. Res. Ther. 46 (3), 375-391. http://dx.doi.org/10.1016/j.brat.2008.01.003.

Van Gucht, D., Vansteenwegen, D., Van den Bergh, O., Beckers, T., 2008b. Conditioned craving cues elicit an automatic approach tendency. Behav. Res. Ther. 46 (10), 1160-1169. http://dx.doi.org/10.1016/j.brat.2008.05.010.

Weike, A.I., Schupp, H.T., Hamm, A.O., 2007. Fear acquisition requires awareness in trace but not delay conditioning. Psychophysiology 44 (1), 170-180. http://dx.doi.org/10. 1111/j.1469-8986.2006.00469.

Winkelmann, T., Grimm, O., Pohlack, S.T., Nees, F., Cacciaglia, R., Dinu-Biringer, R., Flor, H., 2016. Brain morphology correlates of interindividual differences in conditioned fear acquisition and extinction learning. Brain Struct. Funct. 221, 1927-1937. http:// dx.doi.org/10.1007/s00429-015-1013-z. 